\title{
As falhas da Modern Monetary Theory (MMT)
}

\author{
The flaws in Modern Monetary Theory
}

\section{Ricardo Carneiro*}

\begin{abstract}
Resumo
A ascensão inusitada da Modern Monetary Theory (MMT) nos últimos anos, em particular após a crise financeira global de 2008, tornou-a um tema imperativo, tanto do ponto de vista acadêmico quanto no debate de políticas econômicas alternativas. A partir do reconhecimento da sua relevância, este artigo, sem a pretensão de ser exaustivo, aspira realizar uma avaliação crítica das suas principais concepções (i) teóricas, ou seja, o seu entendimento do dinheiro, e (ii) de política econômica, vale dizer, a sua proposta de financiamento do setor público e de uma economia em permanente pleno emprego. Não se busca fazer uma exegese das suas concepções e tampouco realizar análises exaustivas de um de seus aspectos, mas sobretudo, partir de sínteses pouco controversas, para examinar as possíveis consequências de suas propostas de política econômica.
\end{abstract}

Palavras-chave: Teoria Monetária Moderna; Natureza do Dinheiro; Política Econômica; Financiamento do Gasto Público; Pleno Emprego; Bancos; Mercados Financeiros; Especulação.

Classificação JEL: B52; E12; E42; E43; E52; E62

\begin{abstract}
The unusual rise of MMT in recent years, particularly after the 2008 global financial crisis, has made it an imperative issue, both from an academic point of view and in the debate on alternative economic policies. Departing from these facts, this article, without pretending to be exhaustive, aspires to carry out a critical evaluation of its main aspects. Namely (i) its understanding of money, and (ii) its proposal of economic policy, precisely its particular proposal to finance the public sector and to keep the economy in permanent full employment. The article does not seek to make an exegesis of its conceptions, nor does it carry out exhaustive analyzes of one of its aspects, but above all, starting from little controversial syntheses intends to examine the possible consequences of its economic policy proposals.
\end{abstract}

Keywords: Modern Monetary Theory; Nature of Money; Economic Policy; Public Expenditure Financing; Full Employment; Banks; Financial Markets; Speculation.

JEL Classification: B52; E12; E42; E43; E52; E62

\footnotetext{
*Professor Titular do Instituto de Economia da UNICAMP (carneiro@unicamp.br).. auto agradece aos comentários de Luiz Gonzaga Belluzzo; Maria Cristina Penido; Daniela Prates; Bruno De Conti e aos pareceristas anônimos da Brazilian Keynesian Review.
} 


\section{Introdução}

A ascensão inusitada da Modern Monetary Theory (MMT) nos últimos anos, em particular após a crise financeira global de 2008, tornou-a um tema imperativo, tanto do ponto de vista acadêmico quanto no debate de políticas econômicas alternativas. A relevância que adquiriu enquanto substrato de políticas econômicas heterodoxas, discutidas e criticadas por think tanks, instituições financeiras, e publicações acadêmicas, no âmbito do establishment, tornam importante a sua avaliação.

A partir do reconhecimento da relevância da MMT, este artigo realiza uma avaliação crítica das suas principais concepções (i) teóricas, em particular, seu entendimento do dinheiro e do financiamento do setor público (ii) de política econômica, consubstanciada na sua proposta de uma economia em permanente pleno emprego. $\bigcirc$ objetivo é destacar duas importantes lacunas da MMT, que a fragilizam. Essas fragilidades são: uma abordagem parcial do dinheiro, enfatizando o seu caráter estatal e de unidade de conta e meio de pagamento, subestimando a sua dimensão privada e seu caráter de reserva de valor e, na política econômica, a ausência de referência ao contexto histórico do capitalismo contemporâneo, financeirizado.

Criticar as omissões da MMT não nega a sua validade circunstancial. A crise de 2008 inaugurou um período de insolvência bancária e de preferência absoluta pela liquidez exigindo massivas intervenções dos bancos centrais. O período também se caracterizou por uma recusa dos governos dos países capitalistas avançados em usar mais decisivamente o gasto público como mecanismo de estímulo à economia. A relevância da MMT decorre desses fatos. Assim, a sua validade estaria circunscrita ao momento pós-crise e aos países de moeda conversível. Como demonstrado por Prates (2020), na análise da hierarquia do sistema monetário internacional, os países emissores de moeda inconversível com elevada abertura financeira teriam severas dificuldades para pôr em prática o programa de política econômica da MMT.

O caráter contemporâneo da MMT torna-a, às vezes, objeto de disputas e controvérsias, sobre os seus enunciados mais precisos. Nesse texto, embora não se procure examinar cada ponto específico da MMT, cabe explicitar e analisar os seus aspectos gerais. Assim, não se busca fazer uma exegese das suas concepções tal qual em Palley (2020), Henwood (2019), Lavoie (2014), ou Epstein (2019), mas partir de sínteses pouco controversas de autores referenciais da MMT como Wray (2015, 2018) e Lara Resende (2020). 
Para Wray (2015, 2018), se poderia destacar os seguintes aspectos essenciais da MMT:

(i) no que tange à natureza do dinheiro, define-se que ele é uma criatura estatal, uma unidade de conta e meio de pagamento (IOU - I owe you) emitido pelo Estado, e que deriva a sua aceitação da sua capacidade soberana de impor a taxação ao setor privado. Nas palavras dos MMTistas a característica central do dinheiro é ser "tax driven money". Embora haja referências à moeda privada (IOUs), os seus desdobramentos e as relações com o dinheiro estatal não são explorados em detalhe.

(ii) da natureza do dinheiro, seguem-se duas importantes consequências para o financiamento do gasto público corrente, via déficits e para rolagem da dívida pública. $\bigcirc$ gasto antecede a renda, e pode sempre ser financiado pela expansão monetária, a qual será esterilizada posteriormente, em parte pela arrecadação de tributos, em parte por várias formas de dívida. Esta última, por sua vez, não está sujeita a default, seja porque pode ser sempre monetizada, ou porque as taxas de juros são fixadas num patamar inferior ao crescimento da renda. Das proposições acima, decorre uma elevada discricionariedade do Estado na fixação das taxas de juros.

(iii) esta concepção do dinheiro, do financiamento público, e da dívida pública, traz importantes consequências para a política econômica por meio das propostas das finanças funcionais, formulada originalmente por Lerner (1943). Assim, não havendo restrição financeira ao gasto público, a política econômica deve perseguir o pleno emprego. O seu constrangimento seria apenas o da disponibilidade de recursos ociosos e o seu limite, a inflação. Define-se também uma clara preferência pela política fiscal, vis-à-vis a monetária no estabelecimento de estímulos, e mesmo na sintonia fina do ciclo.

Isto posto, este artigo pretende avaliar criticamente a MMT, a partir de duas abordagens. Num primeiro momento, retoma as suas proposições gerais no que tange à concepção do dinheiro na sua forma de moeda fiduciária e soberana (sovereign currency), bem como a postulação de uma economia de pleno emprego embasada nas finanças funcionais. A partir desse quadro de referência, examina-se o funcionamento da economia capitalista a partir de dois circuitos distintos: o do gasto público, financiado monetariamente e o do gasto privado, financiado por crédito. A combinação dos dois circuitos, enquanto aproximação mais rigorosa da realidade, permite sintetizar as críticas principais a MMT. 


\section{A concepção do dinheiro}

Nesse campo, há consenso entre os adeptos da MMT; o dinheiro é uma unidade de conta definida pelo Estado, e meio de pagamento, ou seja, tanto um denominador de bens, serviços, tributos, e contratos como um instrumento de liquidação dessas transações. Caberia ao Estado escolher esta unidade de conta, a moeda e definir as regras, ou o enforcement para a sua circulação. Para além da circulação monetária, a questão essencial seria a da aceitação dessa unidade de conta. Assim, como é uma criatura do Estado, a sua circulação e aceitação dependeriam preponderantemente do fato de que esse dinheiro emitido pelo Estado é utilizado para o pagamento de impostos.

Está-se diante de uma espécie bem definida de dinheiro: o tax driven money. O Estado emite dinheiro, na verdade, um título de crédito - um IOU, na descrição MMtista - que serve para pagar impostos que, por sua vez, derivam da sua capacidade impositiva enquanto Estado soberano. Desse ponto de vista, qualquer agente privado também pode emitir moeda (IOUs), mas o problema residiria na sua aceitação, que no caso do Estado é garantida pelo poder que tem o seu dinheiro de resgatar a dívida tributária.

A postulação acima não está isenta de problemas. Desde logo, como os impostos são apenas uma fração da renda, a aceitação da moeda estatal para fazê-la circular, estaria condicionada por esse limite, requerendo a ajuda da moeda privada. Isto realça a necessidade de um tratamento mais detalhado das relações do dinheiro estatal com o privado, tanto na circulação da renda, quanto no papel mais amplo que tem nas transações privadas, como denominador dos contratos mercantis e financeiros. Desse ponto de vista, é pouco enfatizado pela MMT o fato de o dinheiro também expressar e realizar a circulação da riqueza, como analisado por Keynes (1930) no Treatise on Money por meio da circulação financeira.

O ponto central suscitado pelas observações anteriores é o da limitação que acarreta definir o dinheiro apenas como unidade de conta e IOU. Isto realça seu caráter creditício, de meio de pagamento, ou seja, o dinheiro como poder de compra temporário e instrumento de passagem entre transações mercantis, financeiras e tributárias. Não haveria uma demanda de dinheiro per se, enquanto riqueza ou reserva de valor. Vale dizer, esta concepção minimiza o entesouramento em suas formas históricas particulares. Como se verá a seguir, para a teoria Keynesiana, a dimensão de reserva de valor, ou o dinheiro como riqueza, ou ainda como ativo, é crucial. 
A dimensão de reserva de valor ou do dinheiro como riqueza ou ainda, enquanto ativo, está amplamente tratada por Keynes (1936[2017]) um autor do qual a MMT se pretende herdeira. Na Teoria Geral, há pelo menos três abordagens do assunto: as razões para demandar dinheiro com destaque para a demanda especulativa; a discussão das elasticidades de produção e substituição nulas como propriedades particulares da moeda; a precificação dos ativos a partir das taxas de retorno próprias. Esta última é bastante esclarecedora do assunto aqui em discussão.

A decisão quanto à escolha de ativos formulada por Keynes (1936[2017]) é feita, inicialmente, em termos das taxas próprias de retorno, ou seja, as taxas de retorno de um ativo qualquer medida em termos de si próprio, utilizando-se unidade de conta específica ou numerário. Isso envolveria a consideração de quatro elementos: -(c), (q), (l) e (a): - (c) é a depreciação de um estoque de commodity transportada no tempo, (q) são as quasi-rendas associadas ao ativo instrumental, (l) o prêmio de liquidez ou o prêmio genérico que se cobra pela iliquidez de se sair da moeda. $\bigcirc$ autor também especifica outro elemento (a), que se deve agregar ao retorno dos ativos reais e que representa sua apreciação ou depreciação ante a unidade de conta. Note-se que como Keynes está supondo um padrão monetário estável - sem inflação - este termo representa a mudança de preços relativos dos ativos subjacentes.

O primeiro ponto a observar é que o dinheiro, como qualquer ativo, possui um rendimento próprio. $\bigcirc$ desprendimento da moeda e aquisição de um ativo financeiro de risco zero, por exemplo, envolve a cobrança de um prêmio de liquidez cuja magnitude depende da associada preferência pela liquidez ou da interação entre expectativas altistas e baixistas quanto à alteração das taxas de juros de curto prazo e a decorrente variação nos preços dos títulos. O prêmio de liquidez que Keynes denomina de taxa monetária de juros ou taxa de retorno do dinheiro reflete a incerteza quanto ao valor futuro das outras formas de riqueza, no caso, os títulos sem risco. É o preço para se desprender da forma líquida da riqueza, a moeda.

Sair da moeda para ativos instrumentais ou reais requer a consideração das quasi-rendas (q) e do custo de carregamento (-c). Haveria que acrescentar aqui o termo (a), pensado por Keynes como uma apreciação ou depreciação do ativo ante o padrão monetário. O primeiro, (q), e (-c) estariam associados aos rendimentos e custos de carregamento o segundo (a), a sua mudança de preços relativos. A construção das taxas de retorno do variado espectro de ativos instrumentais e reais se forma pela soma da remuneração (q) e (-c) e as expectativas ou possibilidade de variação patrimonial (a). Há assim para cada ativo particular, moeda, instrumentais, 
e ativos reais taxas de retorno próprias e diferenciadas, a partir das quais se alocam os portfólios.

Se o desenvolvimento keynesiano parasse neste ponto, seria um reforço importante às concepções da MMT. Todavia o raciocínio vai além. Seu exercício teórico não se trata apenas de se compararem taxas de retorno de ativos distintos numa unidade de conta qualquer. $O$ segundo passo é constatar a especificidade do dinheiro como ativo e as peculiaridades da sua taxa de retorno - os juros - mais inflexível à baixa do que a dos demais. Definida a centralidade da taxa monetária de juros Keynes realiza a precificação dos demais ativos, inclusive os títulos, descontando seus fluxos de rendimentos a essa taxa. Com isto, converte as formas particulares de riqueza à sua forma geral, o dinheiro, e elas se tornam comparáveis enquanto riqueza.

Este processo de precificação dos ativos - que supõe a separação radical entre o juro e o lucro enquanto formas de remuneração do dinheiro e dos ativos instrumentais, comum a Marx e a Keynes -está na base da definição da riqueza especulativa. Esta se constitui de ativos cujos preços são calculados a partir do fluxo de rendimentos esperados, descontados à taxa monetária de juros, e que a partir dessa precificação são transacionados em mercados secundários, com diversas consequências, incluindo bolhas de preços e ciclos financeiros.

Outro aspecto falho de definição da moeda na MMT diz respeito à preeminência da forma estatal. A principal forma de moeda privada nas sociedades capitalistas contemporâneas são os depósitos à vista dos bancos. Nas suas variadas versões, a MMT considera a existência da moeda bancária, que denomina do IOU emitido pelos bancos, mas não lhes confere a relevância devida, mormente nas suas relações com o dinheiro estatal. A MMT, teoria que se reivindica minskyana, falha em não explorar mais decididamente as implicações da instabilidade financeira formulada por Minsky (1992), ou seja, do ciclo financeiro construído em base estritamente privada, no qual são decisivos: o crédito, o papel dos bancos, a alavancagem crescente, e o relaxamento das margens de segurança. A questão essencial reside nos condicionantes que este ciclo privado impõe à gestão monetária estatal.

Uma abordagem abrangente do dinheiro deveria considerar, portanto, as duas formas da moeda - pública e privada - suas relações e desdobramentos. A sugestão de Keynes (1930) no Treatise on Money é de considerar a criação passiva de depósitos à vista, que está lastreada na ampliação das reservas bancárias ou moeda estatal e criação ativa, quando se refere à criação de moeda de crédito ex-nihilo, configurando a moeda bancária endógena. Ademais, o dinheiro como forma de 
riqueza, seja ele estatal ou privado, tem um papel crucial na circulação da riqueza financeira, sendo uma de suas formas principais. A existência das duas formas de moeda, a pública e a privada, e a relativa autonomia da última ante à primeira caracteriza o caráter endógeno da moeda privada e, como demonstrado por Chick (1986), cada vez mais autônoma ante a base de reservas bancárias produzindo recorrentemente a especulação e a fragilidade financeira.

A partir desta concepção de dinheiro, a MMT define a determinação da taxa de juros, na qual a autoridade monetária tem amplo poder discricionário na fixação daquelas de curto prazo, da qual se derivaria o espectro das taxas de médio e longo prazos. Na verdade, a tese é a de que o espectro de taxas de juros é desdobramento da taxa de curto prazo, incorporando expectativas inflacionárias, não cabendo ao mercado, papel relevante na sua fixação, como defende seu principal autor, Randall Wray (2018), inequívoco defensor da ZIRP (zero interest rate policy).

Algumas vertentes MMTistas contestam essa afirmação dado que o assunto é marcado por certa ambiguidade. De qualquer modo, a natureza do dinheiro, o não constrangimento financeiro do setor público, a impossibilidade de default do emissor da moeda soberana, e a sustentabilidade da dívida pública ancorada no pressuposto de que a taxa de juros deve ser menor do que o crescimento da renda, quatro pilares da MMT, levam necessariamente à interpretação do caráter fortemente discricionário na fixação do espectro das taxas de juros.

Outras variantes, como Lara Resende (2020), consideram que poderia haver alterações temporárias nessa discricionariedade, ocorrendo variação mais ampla dos spreads entre taxas curtas e longas, mas em circunstâncias excepcionais. Aqui, algumas observações são pertinentes. Primeiro, com tal concepção do dinheiro, a noção de preferência pela liquidez, que reflete o papel do mercado na determinação das taxas de juros, é minimizada. Ora, mas o que está em jogo na preferência pela liquidez é a escolha dos proprietários da riqueza no que diz respeito a mantê-la na forma mais ou menos líquida. Ela é reflexo das incertezas quanto à trajetória futura das taxas de juros e expressa as expectativas do mercado quanto ao comportamento prospectivo de variáveis econômicas cruciais, incluindo a ação do Banco Central.

Cabe aqui recordar que para os detentores da riqueza financeira, a composição de seus portfólios entre títulos de diversas maturidades implica perdas e ganhos de capital, via marcação a mercado, quando o espectro de taxas de juros se altera. A inclinação dessa curva - ou seja, os spreads das diversas taxas ante a taxa básica são flutuantes ao longo do tempo - reflete, como mencionado, incertezas e o predomínio de posições altistas ou baixistas entre os proprietários da riqueza. Para além do tamanho e flutuação desses spreads, que traduz o sentimento do mercado 
na negociação dos títulos de dívida em mercados secundários líquidos, na determinação das taxas longas, observa-se também momentos de ruptura ou de extrema polarização das convenções. Eles acontecem ou na inversão da curva de juros, com taxas curtas maiores do que as longas, ou contrariamente na sua forte inclinação positiva.

primeiro fenômeno expressa a polarização altista, ou seja, expectativas fortemente predominantes de que a taxa longa cairá por eventual recessão futura e a certeza de que o BC reduzirá a taxa curta. Assim, os agentes mudam seus portfólios comprando títulos longos e derrubando as taxas correspondentes. $O$ segundo movimento é a tradução da preferência absoluta pela liquidez na qual prevalece a polarização baixista, ou seja, a posição de que por variadas razões - por exemplo, por uma avaliação de riscos crescentes de financiamento dos setores público ou privado - as taxas longas subirão inexoravelmente. Segue-se a venda de títulos longos e a subida dos juros correspondentes.

Os adeptos da MMT poderiam arguir que a intervenção do BC ao longo de toda curva de juros, comprando e vendendo títulos, fixaria os juros nas várias maturidades e eliminaria a incerteza quanto ao seu comportamento futuro. Poderiam usar como exemplo o caso da política monetária não convencional, o quantitative easing, posta em prática em larga escala, após a crise financeira global de 2008, cujo sentido foi exatamente o da intervenção do BC nos mercados de títulos para evitar a insolvência e regular o espectro de taxas de juros, utilizando para isto a emissão monetária. Contudo, se foi possível, num momento de crise profunda e de preferência absoluta pela liquidez, utilizar em tal grau o poder de intervenção do Estado nos mercados financeiros, o processo não esteve isento de graves efeitos colaterais. Além dos problemas da histerese, a política não convencional engendrou problemas de outra natureza: as bolhas de preços de ativos em mercados líquidos e radicalmente desregulados.

\section{O financiamento de déficits e as dívidas}

A concepção de dinheiro tem implicações sobre como, por quais meios, e em quais quantidades, a moeda entra em circulação. Desde logo, a MMT discute de maneira privilegiada a moeda soberano ou estatal e fiduciária dando menos ênfase a moeda bancária privada. No desdobramento da análise, preocupa-se primordialmente com as variações da quantidade de moeda associada ao gasto público, em particular injetado na economia via déficit, e sua esterilização com o pagamento de impostos. 
A MMT certamente não desconhece a existência de outras formas de expansão da moeda, mas não lhes confere a importância necessária. Assim, não é ocioso destacar essas formas e sua autonomia relativa. Numa economia aberta financeiramente, as operações cambiais são cruciais e determinadas por variáveis independentes, como o ciclo de liquidez. $\bigcirc$ tratamento dado pela MMT ao setor externo, tal qual exposto por Wray (2015), é insuficiente e concentrado na balança comercial e de transações correntes, ou nos fluxos líquidos de capitais. Omite as abordagens contemporâneas relevantes, como as de Borio e Disyatat (2010), por exemplo, nas quais o aspecto central da trajetória dos balanços de pagamentos contemporâneos é a conta de capital e os fluxos brutos.

As operações de injeção e retirada de liquidez por parte do Banco Central (doravante BC) via depósitos compulsórios, ou compra e venda de títulos curtos, são também essenciais e podem responder a decisões de política econômica ou demandas irrecusáveis do setor bancário. Ou seja, podem decorrer de expansão excessiva dos empréstimos bancários e de uma crise de liquidez que eventualmente pode se converter em sistêmica. Os BC's sempre foram prisioneiros, de uma ou de outra forma, da validação da moeda criada pelos bancos, na sua função de emprestador de última instância. Mas, o fato é que a financeirização e a crise financeira de 2008 ampliaram em muito a necessidade e o espectro desta atuação, levando-a para o plano da solvência. Como a MMT interpretaria isso? Como um aumento da discricionariedade dos BC ou como seu aprisionamento às vicissitudes do ciclo de expansão monetária e financeira do setor privado?

A dimensão privilegiada da expansão e contração monetária abordada pela MMT é aquela que diz respeito à ampliação, resgate, e rolagem da dívida pública soberana emitida em moeda doméstica. Ou seja, de acordo com suas concepções não há restrição financeira ao gasto público e, portanto, ao financiamento monetário e à rolagem da dessa dívida pública - que pode ser sempre monetizada - sendo o default opção desnecessária e descartável.

No financiamento da dívida, cabe distinguir a rolagem do principal (estoque), da carga de juros (fluxos), e do saldo primário. A rolagem, em tese, não acarretaria maiores implicações macroeconômicas caso não haja mudanças significativas na alocação de portfólio dos agentes privados, pois ela representa apenas uma renovação. $\bigcirc$ pagamento ou a amortização e, portanto, a criação de moeda é prévia à sua recaptura por meio da emissão de novos títulos. Mas, mesmo nesse caso, esta renovação está sujeita a mudanças de prazos e juros e o seu resultado dependerá do poder relativo do Tesouro vis-à-vis a preferência pela liquidez dos rentistas. 
Outra questão é o financiamento da carga de juros. Diferentemente do principal da dívida, a carga de juros não é a contrapartida de emissão monetária prévia, nem implica exercício de demanda efetiva como no déficit primário. Ao contrário do principal da dívida, que já ocupava espaço na riqueza ou poupança financeira e nos portfólios privados, a carga de juros disputará o fluxo novo de poupança sem ter contribuído para seu aumento. A questão essencial é: déficits primários geram a poupança macroeconômica necessária para seu financiamento, mas, ceteris paribus, não o garantem, nas condições prévias. A carga de juros, o outro componente do déficit nominal, ao não se constituir como demanda efetiva, não gera fluxo adicional de poupança macroeconômica para financiá-la. Seu financiamento potencial exige aumento compatível do PIB ou mudanças nos portfólios privados e nas taxas de juros.

Autores adeptos da MMT, como Lara Resende (2020), reconhecem o problema da sustentabilidade da dívida e propõem que o caráter não desestabilizador do seu crescimento e rolagem estaria dado pela regra de ouro, ou seja, por uma taxa de juros implícita menor do que o crescimento do PIB, associado a um saldo primário nulo. Isto levaria a uma diluição da dívida, ou seja, uma redução da relação dívida/PIB ao longo do tempo. Como o BC fixa as taxas de juros, isto estaria garantido. Por esta condição garante-se tanto o financiamento, pela existência da poupança necessária, quanto a ausência de custo fiscal, ou seja, de superávit primário para estabilizar a dívida.

A postulação de Lara Resende (2020) toma por base a expressão:

$$
\mathrm{d}=(\mathrm{r}+\mathrm{s})-\mathrm{g}
$$

Em que (d) é o crescimento dívida pública, (r) é a taxa de juros, (s) o saldo primário, e (g) a taxa de crescimento do PIB. A expressão é uma identidade que mostra em cada ponto do tempo quais os responsáveis pelo crescimento da dívida. Assim, por exemplo, a estabilidade ou crescimento zero da dívida seria obtida por saldo primário nulo e pela igualdade entre taxa de juros e crescimento do PIB. Todavia, é necessário esclarecer que esta, como quaisquer das postulações sobre a trajetória da dívida, deve ser considerada como uma hipótese dentre outras, cuja explicação deve ser encontrada no campo econômico-financeiro e não em identidades contábeis.

Assim, parece contraditório para adeptos da MMT formular como hipótese de estabilidade da dívida situações de saldo primário nulo. $\bigcirc$ papel dos déficits continuados é central para o programa de política econômica da MMT. Seria mais correto formular a hipótese de que a estabilização da dívida dependeria de: 


$$
\mathrm{r}+\mathrm{s}=\mathrm{g}
$$

Ou seja, o crescimento do PIB teria que igualar o déficit nominal, o que é uma condição mais difícil de ser cumprida. Isto atende também a condição de que é necessário, ceteris paribus, déficit primário para que a renda cresça e, com ela aumente a arrecadação, que esteriliza parte da emissão inicial, somada à poupança adicional que financiaria, em princípio, o déficit primário. Sobra ser refinanciada, sem o correspondente aporte da poupança gerada no circuito gasto público-renda, a carga de juros. A condição da equação (2) atende, pelo menos, a condição de que haverá poupança macroeconômica disponível para financiar o déficit nominal. É incerto em quais condições de juros e prazos isto será feito.

Caso se olhe a expressão (1) não como uma identidade, mas como função de variáveis interdependentes ou correlacionadas, a questão se torna bastante complexa. Por exemplo, fica difícil especificar o crescimento da dívida como uma função das demais variáveis, na medida em que sua trajetória também determina as variáveis independentes, sobretudo a taxa de juros. Ademais, essas últimas possuem elevado grau de correlação entre si, como os pares $(s, g)$, (s, r), ou (r, g). A solução pode ser escolher uma âncora para o sistema e supor que não seja afetada pelo próprio crescimento da dívida: a ortodoxia elege o saldo primário, os keynesianos o crescimento do PIB, e a MMT, a taxa de juros.

\section{O programa de política econômica}

Associado à concepção de dinheiro, financiamento dos déficits, e rolagem da dívida, a contribuição da finança funcional de Lerner (1943), a MMT formula o seu programa de política econômica, cujo desiderato é uma economia com pleno emprego, em parte obtido por meio do Estado como empregador de última instância. $\bigcirc$ instrumento central para consecução desse objetivo seria a política fiscal, em particular o gasto público. A política monetária teria papel secundário - caracterizado por uma política de juros baixos e liquidez farta - inclusive na sintonia fina do ciclo, a qual caberia também à política fiscal realizar.

Do ponto de vista do objetivo proposto pela MMT, uma primeira crítica diz respeito ao seu caráter irrealista. Nas sociedades capitalistas, o desemprego funciona como elemento disciplinador da força de trabalho. $\bigcirc$ ponto já havia sido anotado por Kalecki (1943), num ensaio clássico, no qual alertava para o fato de que o crescente controle obtido pelo estado sobre a demanda agregada não implicaria que este fosse utilizado em benefício dos trabalhadores. Essa perspectiva é ampliada por Streeck (2013), na análise que faz da derrocada do regime de Bretton Woods. Para ele, os fatores preponderantes de sua extinção foram a crescente perda de controle 
sobre a força de trabalho, os movimentos sociais, e particularmente o movimento sindical, emponderados por mais de duas décadas de aumentos de salários, benefícios sociais, e autonomia organizativa.

O programa de emprego garantido da MMT tem dificuldades operacionais significativas. Conforme assinalado por Wray (2015), ele não se confundiria com um programa de renda mínima, tampouco com um seguro-desemprego, mas se constituiria num processo de mobilização de força de trabalho, que receberia salário homogêneo para a realização de determinadas tarefas. Para além da definição sobre o que fariam essas frentes de trabalho, a organização e gerenciamento desses contingentes elevados de trabalhadores por períodos relativamente longos é tarefa de grande dificuldade.

Outra omissão importante da MMT no seu programa de política econômica diz respeito à ausência de referências à financeirização, sobretudo no que tange à crescente desregulação e liquidez dos mercados financeiros. De acordo com vasta literatura - ver por exemplo Carneiro (2020) para uma resenha - o padrão do capitalismo financeirizado tem sido o da valorização da riqueza - fictícia ou especulativa - determinar a trajetória da renda. Haveria, portanto, que discutir a fundo os efeitos da expansão monetária não só sobre a renda, mas sobretudo sobre a riqueza. Ou seja, os efeitos da expansão monetária teriam que ser considerados não só no que tange ao crescimento da renda e a inflação de bens e serviços, mas principalmente nos seus impactos sobre a evolução dos preços dos ativos.

Há outros aspectos problemáticos na formulação do programa de política econômica da MMT dentre os quais o pressuposto da fusão do BC com o Tesouro, numa única instituição. Mas, isto é uma postulação a-histórica. As relações entre essas duas instituições comportam uma gama de situações variáveis, refletindo a história concreta dos países e correlações de força distintas entre grupos empresariais - em particular os rentistas - e o Estado. Na prática, o que se tem observado no período recente, por força da financeirização e do poder ampliado dos rentistas é a generalização do BC autônomo ou independente. O exemplo contemporâneo, como os EUA e dos países desenvolvidos, mostra BC muito solícitos a desempenhar suas funções de emprestadores de última instância para salvar a riqueza privada. Todavia, o financiamento monetário de programas de pleno emprego não constitui parte do cardápio de suas intervenções. 


\section{O financiamento monetário do déficit}

Delineados os princípios analíticos relevantes da MMT, seguem agora alguns circuitos possíveis. A separação aqui entre dois circuitos distintos, o do gasto ou déficit público, financiado com emissão monetária estatal, e do gasto privado, financiado com moeda bancária, é apenas simplificação analítica, pois, na prática, eles são indissociáveis. Isso posto, inicie-se a análise com o circuito de financiamento monetário do déficit, por meio dos balanços de uma autoridade monetária-fiscal unificada, tal qual sugerido pela MMT e, posteriormente, dos bancos privados (Diagrama 1). Adote-se também a proposição da MMT de que o gasto antecede a renda e a tributação. Por suposição adicional, este gasto se direciona para um programa de pagamento de remunerações para sustentar o pleno emprego.

O primeiro passo do processo (1) é a emissão de moeda pelo BC/Tesouro para financiar o gasto, aumentando seu passivo monetário. Este montante entra nas reservas bancárias ampliando-as e tem como contrapartida o aumento dos depósitos à vista nas contas dos beneficiários. Estamos diante do que Keynes denominou de criação passiva de depósitos bancários, na verdade uma forma secundária de criação de moeda nas economias capitalistas e própria dos sistemas bancários primitivos segundo Chick (1986).

O segundo passo (2) é o desdobramento da injeção desse poder de compra na economia, o crescimento da renda via efeito multiplicador. Do ponto de vista do sistema bancário, à medida que se processa a cadeia de pagamentos, os depósitos à vista mudam de titularidade. O processo finaliza (3) com a mudança definitiva da titularidade dos depósitos à vista que assumem a forma de poupança financeira lucro das empresas, por exemplo - e dívida tributária (impostos a serem pagos). Ainda nessa etapa cabe assinalar que a renda, um fluxo que se viu ampliado, gerou a poupança ou riqueza, ainda na forma de depósitos à vista. A preservação do patamar da renda dependerá da realização de novos gastos autônomos, oriundos seja da renovação do déficit, seja do gasto privado, nesse caso alimentado a crédito. 
Diagrama 1. Balanços da autoridade monetária-fiscal e bancos privados

\begin{tabular}{|c|c|c|c|}
\hline \multicolumn{2}{|c|}{ Tesouro + Banco central } & \multicolumn{2}{|c|}{ Bancos Privados } \\
\hline ATIVO & PASSIVO & ATIVO & PASSIVO \\
\hline$\Longrightarrow$ & $\begin{array}{l}\text { 1. Financiamento } \\
\text { monetário de déficit }\end{array}$ & $\begin{array}{l}\text { 1. Ampliação de } \\
\text { reservas bancárias }\end{array}$ & $\begin{array}{l}\text { 1. Depósitos à vista } \\
\text { na conta de } \\
\text { beneficiários }\end{array}$ \\
\hline & & & $\begin{array}{l}\text { 2. Transferências de } \\
\text { titularidade - } \\
\text { circulação da renda }\end{array}$ \\
\hline & & & $\begin{array}{l}\text { 3. Titularidade final: } \\
\text { lucro + impostos } \\
\text { devidos }\end{array}$ \\
\hline & $\begin{array}{l}\text { 4. Cancelamento } \\
\text { parcial da emissão } \\
\text { monetária }\end{array}$ & $\begin{array}{l}\text { 4. cancelamento } \\
\text { parcial das reservas } \\
\text { bancárias }\end{array}$ & $\begin{array}{l}\text { 4. Pagamento de } \\
\text { impostos }\end{array}$ \\
\hline & $\begin{array}{l}\text { 5. Venda de títulos } \\
\text { públicos ou } \\
\text { Depósitos } \\
\text { remunerados no BC }\end{array}$ & $\begin{array}{l}\text { 5. esterilização das } \\
\text { reservas } \\
\text { remanescentes }\end{array}$ & $\Longleftarrow$ \\
\hline & $\begin{array}{l}\text { 6.1. aumento dos } \\
\text { DRs } \\
\text { 6.2. aumento de } \\
\text { títulos em poder do } \\
\text { público } \\
\text { 6.3. aumento do } \\
\text { valor dos títulos em } \\
\text { poder do público }\end{array}$ & $\begin{array}{l}\text { 6.1. esterilização de } \\
\text { curto prazo } \\
\text { 6.2. esterilização por } \\
\text { título e } \\
\text { cancelamento de } \\
\text { ativo bancário } \\
\text { 6.3. esterilização de } \\
\text { curto prazo }\end{array}$ & $\begin{array}{l}6 \text { Uso da poupança } \\
\text { financeira } \\
6.1 \text {. Depósitos à vista } \\
6.2 \text { Título novo e } \\
\text { cancelamento de D.V } \\
6.3 \text { Título velho e } \\
\text { mudança de } \\
\text { titularidade dos D.V }\end{array}$ \\
\hline
\end{tabular}

Na etapa (4), uma parte da renda transformada em impostos - que também pode incidir sobre a riqueza - será paga ao Tesouro-BC. A operação cancela valor correspondente dos passivos e das reservas bancárias e da emissão monetária inicial. Importante notar que o cancelamento é apenas parcial, pois restam os recursos correspondentes à diferença entre gasto (ou seja, renda) e tributação e que, nesse caso, se refere à poupança privada. Ela está no ativo dos bancos sob a forma de reservas, em dinheiro estatal, mas também no seu passivo, sob a forma de depósitos à vista de propriedade de capitalistas.

Para ter controle sobre a taxa de juros de curto prazo, o BC-Tesouro tem que regular as reservas bancárias - circuito (5). Nesse caso, como elas foram ampliadas, há que esterilizá-las para evitar que as operações de empréstimos interbancários façam cair a taxa de juros básica abaixo do desejado pelo BC. Se essa taxa de juros for zero, a operação não será necessária. Caso contrário, três possibilidades se colocam: realizar a esterilização por operações compromissadas (repos), ou depósitos remunerados no $\mathrm{BC}$, com liquidez imediata, ou fazer esta esterilização por meio de venda definitiva de títulos públicos.

A MMT vê pouca distinção entre as diversas operações de esterilização, exceto, seu diferencial de liquidez. Na verdade, ambas não representariam operações de financiamento do gasto público já que este foi previamente realizado com expansão monetária. Contudo, como esta não é capturada integralmente pela tributação é necessário esterilizá-la. Mesmo que isto seja correto, há importantes 
diferenças a assinalar. A captura via depósitos remunerados ou compromissadas envolve a relação entre bancos e $\mathrm{BC}$-Tesouro. A hipótese de que os bancos aceitarão sempre a taxa de juros proposta pelo BC, pois não têm uso alternativo para as reservas bancárias, é questionável, como se verá a seguir. Também é difícil aceitar que na esterilização por títulos públicos por meio de dealers no mercado primário, o Estado tenha poder discricionário absoluto para determinar a taxa de juros. Esse financiamento somado à rolagem do estoque da dívida e da carga de juros, referido acima, pode se revelar problemático.

Afirmar que os detentores de riqueza não têm alternativa é também discutível. Isto porque as taxas de juros correspondentes às diversas maturidades dos títulos públicos são determinadas nos mercados secundários. Se o Tesouro estabelecer taxas de juros nas negociações primárias distintas daquelas dos mercados secundários pode não vender seus títulos. Pode apelar ao Banco Central para que adquira os títulos com emissão monetária, mas mesmo nesse caso extremo deixará aos proprietários da riqueza a alternativa dos títulos já em circulação. Estes podem optar por títulos públicos, privados, ou mesmo ativos reais.

De acordo com Lara Resende (2020), a questão da dívida e de seu custo se resolve exatamente pelo poder discricionário do Estado em fixar a taxa de juros, ancorada na sua prerrogativa do financiamento monetário e na monetização da dívida em títulos. Para o autor, não haveria diferença entre moeda e títulos pois, ambos, são passivos do governo dotados de plena liquidez. Segundo Lara Resende (2020), a diferença de remuneração dos títulos ante a moeda seria apenas uma concessão desnecessária aos rentistas na medida em que toda dívida poderia assumir a forma de depósitos remunerados, altamente líquidos, no Banco Central. Essa proposição, para ser aceita, deveria responder a três questões distintas: quais seriam os efeitos sobre os estoques de dívidas, pública e privadas, de uma dívida pública integralmente líquida? Nesse caso, a liquidez da moeda não é distinta daquela dos mercados secundários de títulos, ou estes já incorporam o BC como monetizador, em primeira instância? Sem curva de juros de títulos públicos, como fica o cálculo dos juros longos cobrados pelos bancos e intermediários financeiros nos financiamentos privados?

Para a MMT, o circuito se encerraria aqui nesse ponto (5), com a esterilização, temporária via repos, ou depósitos remunerados ou, mais duradoura via venda definitiva de títulos, mas com taxas de juros estritamente controladas. No primeiro caso, que envolve operações curtíssimas nas quais de fato o Estado goza de maior discricionariedade, a alternativa possível para os bancos - em operações curtas - ou para os detentores da riqueza em geral - em operações mais longas - é a operação 
cambial de conversão da moeda doméstica em divisas, uma forma de esterilização que como assinalado por Carneiro e De Conti (2020) tem impactos cruciais, para moedas periféricas implicando ceteris paribus, desvalorizações da moeda local. A desvalorização da moeda doméstica impõe para os agentes endividados em moeda reserva o currency mismatch, implicando desequilíbrios de balanço de graus variados. Ao mesmo tempo, implica efeitos no nível de preços domésticos por conta da fixação de vários preços relevantes em moeda reserva, o denominado passtrough.

Evitar a conversão da moeda doméstica, no caso, as reservas bancárias, em divisas pode ser um importante objetivo da política econômica para contrabalançar a decisão dos bancos ou dos proprietários dos depósitos bancários. Com mercados cambiais liberalizados, a forma principal de fazê-lo é aumentando a taxa de juros doméstica. De acordo com a teoria da paridade descoberta da taxa de juros, em tese, diante de uma desvalorização cambial inicial, a taxa interna terá que subir até o ponto em que elimine a expectativa de sua desvalorização adicional. Nas moedas periféricas, o padrão de flutuação das taxas de câmbio costuma se caracterizar por uma trajetória de overshooting, o que constitui constrangimento decisivo para a fixação da taxa de juros doméstica. $\bigcirc$ poder discricionário do BC-Tesouro de fixar a taxa de juros curta fica assim relativizado. A MMT, de acordo com Wray (2015) não reconhece a validade desta possibilidade ao adotar a hipótese do trilema como uma boa representação do policy space de países emissores de moeda periférica.

O último segmento do circuito do financiamento monetário do déficit diz respeito ao uso da poupança privada resultante do processo (6). $\bigcirc$ proprietário da riqueza financeira, seja ela lucro acumulado das empresas seja poupança das famílias, terá várias alternativas. A primeira delas, a pouco provável (6.1), é manter a sua riqueza sob a forma de depósitos à vista no sistema bancário ao qual corresponderá a esterilização de reservas bancárias junto ao BC-Tesouro. A segunda alternativa (6.2), ainda em acordo com a MMT, é a de que o proprietário da riqueza aceite a taxa de juros oferecida pelos títulos públicos. Nesse caso, adquire o título público cancelando depósito à vista que terá como contrapartida a esterilização definitiva de reservas bancárias, transferidas ao Tesouro-BC que amplia a quantidade de títulos em circulação em poder do público.

$\bigcirc$ final feliz apontado acima nem sempre ocorre. $\bigcirc$ proprietário da riqueza pode, por exemplo, julgar insuficiente a taxa de juros oferecida pelo título público de nova emissão. Aqui há duas hipóteses: a primeira, como já visto, diz respeito à compra de moeda ou títulos no exterior, com as consequências já apontadas; a segunda pode dizer respeito à aposta de valorização dos títulos (fique-se por ora nos públicos) já emitidos e que circulam no mercado secundário. Nesse caso (6.3.), o 
proprietário da riqueza compra títulos já existentes, transferindo ao antigo proprietário os depósitos à vista. Ademais, também não há perda de reservas bancárias que podem ser esterilizadas por operações curtas. Isto também não altera o passivo em títulos do Tesouro-BC, mas amplia o valor dos títulos já em circulação. Esta hipótese que descreve um processo especulativo, parece ser extremamente favorável às teses da MMT. O fluxo novo de poupança usado para comprar títulos já em circulação elevará os seus preços com a correspondente queda das taxas juros. A redução das taxas longas por um processo de mercado favorece a captura das reservas bancárias pela taxa curta, sugerindo ampliação da discricionariedade do Tesouro-BC.

$\mathrm{Na}$ verdade, foi feita uma escolha por parte do proprietário da riqueza para não adquirir novos títulos e parte do novo gasto terá assim que ser monetizado. No caso do gasto público, isto pode não parecer grave na medida em que este financiamento é feito pela esterilização das reservas bancárias. Há dois senões nesta conclusão: primeiro, a especulação que pode ocorrer em mercados diversos, e não apenas nos títulos públicos, engendrando bolhas especulativas de intensidade variada. Segundo, a liquefação da estrutura de financiamento do setor público. Ambos os senões, como se verá adiante, acarretam eventuais dificuldades ao financiamento do investimento privado.

\section{O financiamento do gasto privado por crédito}

Nesse caso, examina-se o circuito do financiamento do gasto privado por meio da moeda criada endogenamente pelos bancos, num procedimento denominado por Keynes de criação ativa de depósitos, ou seja, empréstimos criam depósitos (Diagrama 2). Em suas análises, Keynes (1937) se refere ao finance, um fundo rotativo, de caráter nocional, a partir do qual empréstimos de curto prazo criavam depósitos à vista cuja titularidade mudava com o multiplicador da renda até o ponto em que os tomadores de empréstimos, quando lhes retornam depósitos, pagavam as suas dívidas, cancelando ambos. Trata-se de criação de moeda bancária - um IOU como diria a MMT - e sua implicação é tornar bancos menos líquidos e mais alavancados.

Como apontado por Carneiro (2009), o finance distingue-se do funding que é uma operação de captura da poupança macroeconômica criada previamente pelo finance bancário, ou pela expansão monetária. No funding, os bancos não criam moeda, apenas fazem a sua intermediação compatibilizando prazos e juros da riqueza dos proprietários que está no passivo bancário - inicialmente sob a forma de depósitos à vista, tal qual no caso anterior - com emissão de títulos de dívida mais longos. Com base nesses recursos consolidam financiamentos longos, em geral para 
formação de capital. Em países com mercado de capitais desenvolvidos, este segmento tem parcela expressiva das operações fora dos balanços bancários.

○ circuito da moeda bancária se inicia com a concessão de empréstimos para a produção (1) e o consequente crédito dos depósitos à vista para os titulares. A geração e circulação da renda vai mudando a titularidade dos depósitos (2). Nesse interim, o sistema bancário pode eventualmente descobrir que emprestou demais e que está indesejavelmente ilíquido. $\bigcirc$ primeiro sintoma disto será a elevação das taxas de juros no mercado interbancário. Logo, para evitar que isto aconteça, o Tesouro-BC amplia liquidez por formas canônicas: compra de títulos curtos ou redução do compulsório. Esta etapa (3) se encerra com a titularidade dos depósitos à vista nas mãos dos devedores que realizam o pagamento dos empréstimos, levando ao seu cancelamento no ativo dos bancos. Note-se que a ação do BC se circunscreveu aqui apenas à assistência de liquidez, sendo, portanto, limitada.

A ampliação do gasto, seja público seja privado, faz operar o multiplicador da renda e deixa ao final do processo uma poupança de igual magnitude -nesse caso, integralmente nas mãos dos capitalistas que são seus proprietários (4). Abrem-se a partir daí duas alternativas: a primeira (4.1), seria a subscrição, por parte desses últimos, de depósitos a prazo. Do ponto de vista contábil, nos passivos bancários, os depósitos à vista se transformam em depósitos a prazo, e nos ativos, empréstimos curtos em empréstimos longos. Isto permitiria aos bancos financiar capitalistas que estariam, por exemplo, ampliando capacidade produtiva. Mas, esta transformação de prazos não está garantida. $\bigcirc$ proprietário da poupança financeira (riqueza) terá que aceitar as taxas de juros na subscrição de títulos privados, necessariamente baixas e próximas das fixadas pelo BC-Tesouro, de acordo com a MMT, acrescidas de um spread de risco, para ceder sua riqueza financeira por prazo mais longo. Isto é uma condição sine qua non para que o empresário demande os recursos, pois está adquirindo instalações ilíquidas e com prazo longo de depreciação. As taxas baixas de juros, nesse caso, exercem efeito contraditório: estimulam a demanda, mas podem restringir a oferta de funding. Em mercados regulados, com direcionamento do crédito esse percalço poderia ser resolvido, mas em mercados desregulados, cria a possibilidade do uso alternativo desse funding. 


\section{Diagrama 2. Balanços da autoridade monetária-fiscal e bancos privados}

\begin{tabular}{|c|c|c|c|}
\hline \multicolumn{2}{|c|}{ Tesouro + Banco central } & \multicolumn{2}{|c|}{ Bancos Privados } \\
\hline ATIVO & PASSIVO & ATIVO & PASSIVO \\
\hline & & $\begin{array}{l}\text { 1. Concessão de } \\
\text { empréstimos de curto } \\
\text { prazo para produção } \\
\stackrel{\longrightarrow}{\longrightarrow}\end{array}$ & $\begin{array}{l}\text { 1. Criação de depósitos } \\
\text { à vista }\end{array}$ \\
\hline & $\begin{array}{l}\text { 2. Aumento da liquidez } \\
\text { por redução de } \\
\text { compulsório ou } \\
\text { cancelamento de } \\
\text { compromissadas }\end{array}$ & $\begin{array}{l}\text { 2. excesso de lliquidez } \\
\text { indesejada }\end{array}$ & $\begin{array}{l}\text { 2. Transferência de } \\
\text { titularidade, circulação } \\
\text { da renda }\end{array}$ \\
\hline & & $\begin{array}{l}\text { 3. Liquidação e } \\
\text { cancelamento de } \\
\text { empréstimos curtos }\end{array}$ & $\begin{array}{l}\text { 3. Posse de depósitos à } \\
\text { vista pelos } \\
\text { prestatários, cancela } \\
\text { D.V }\end{array}$ \\
\hline & & $\begin{array}{l}\text { 4.1 Concessão de } \\
\text { empréstimo de L.P. } \\
\text { 4.2Desintermediação }\end{array}$ & $\begin{array}{l}\text { 4. Poupança financeira } \\
\text { 4.1 Depósito a prazo } \\
4.2 \text { Compra de títulos } \\
\text { já emitidos com } \\
\text { redepósitos de D.V }\end{array}$ \\
\hline & & $\begin{array}{l}\text { 5. Concessão de } \\
\text { empréstimos para } \\
\text { especulação }\end{array}$ & $\begin{array}{l}\text { 5. Criação de depósitos } \\
\text { à vista }\end{array}$ \\
\hline & $\begin{array}{l}\text { 6. Aumento da liquidez } \\
\text { por redução de } \\
\text { compulsório ou } \\
\text { cancelamento de } \\
\text { compromissada }\end{array}$ & $\begin{array}{l}\text { 6. Desintermediação e } \\
\text { renovação de } \\
\text { empréstimos curtos }\end{array}$ & $\begin{array}{l}\text { 6. Transferência de } \\
\text { titularidade dos D.V }\end{array}$ \\
\hline & & $\begin{array}{l}\text { 7. Pagamento e } \\
\text { cancelamento do } \\
\text { empréstimo para } \\
\text { especulação }\end{array}$ & $\begin{array}{l}\text { 7. Transferência final } \\
\text { de titularidade dos D.V }\end{array}$ \\
\hline $\begin{array}{l}\text { 8. Títulos públicos e } \\
\text { privados }\end{array}$ & $\stackrel{\text { 8. Emissão monetária }}{\longrightarrow}$ & $\begin{array}{l}\text { 8. Troca de títulos por } \\
\text { reservas bancárias }\end{array}$ & \\
\hline
\end{tabular}

Fonte: Elaboração própria.

O problema maior nessa etapa é que a decisão do proprietário da riqueza é crucial. Ele pode, por exemplo, decidir adquirir títulos já existentes apostando que sua valorização excederá a taxa de juros oferecida pelos novos títulos. Nesse caso (4.2) a poupança será dirigida para especulação, havendo troca de titularidade de depósitos à vista e de propriedade dos títulos já em circulação. Não há aqui nenhuma diferença do caso (6.3) indicado na ampliação do gasto público. $\bigcirc$ paradoxo é que quanto menor a taxa de juros - num contexto de mercados financeiros líquidos e desregulados - maior será o incentivo para que os proprietários da riqueza busquem sua valorização, via aquisição dos títulos em mercados secundários, ou seja por meio da especulação e não do financiamento, nos mercados primários. A especulação é favorecida por contextos de taxas de juros baixas, por corresponderem a preços de títulos mais elevados em decorrência da forma de precificação dos títulos. 
Adicionalmente, movimentos de queda das taxas de juros sancionam a especulação por conta da elevação dos preços desses últimos devido a marcação a mercado.

Obviamente, isto não impede, tout court a expansão dos novos financiamentos, mas como alerta o FMI (2019), em relatório que tem o sugestivo título "Lower for longer", a busca de taxas de retorno mais altas, além de direcionar o funding para a especulação, conferiu importância crescente dos financiamentos por junk bonds e créditos bancários sem garantia. Ou seja, taxas de retorno mais elevadas só podem ser obtidas na especulação ou no financiamento para devedores de maior risco, ampliando a fragilidade financeira. Talvez fosse o caso de a MMT concluir que tanto a regulação dos mercados quanto o direcionamento do crédito seriam as condições suficientes para viabilizar os baixos patamares de taxas de juros implícita nas suas propostas.

Cabe examinar, por fim, a possibilidade de concessão de empréstimos diretamente à especulação por parte dos bancos. Não há distinção do finance dirigido à produção (5). A compra de títulos de riqueza já existentes requer a transferência de titularidade dos depósitos à vista e dos títulos, mas nesse caso é necessária a renovação dos empréstimos curtos (6). Importante notar que nesse caso a especulação liberta-se dos limites impostos pela poupança macroeconômica. cancelamento do processo (7) ocorre quando o proprietário da riqueza a vende no mercado de capitais e liquida seus empréstimos curtos junto ao banco.

Dependendo da escala nas quais os bancos se envolveram neste processo, crises de liquidez pontuais, ou mesmo sistêmicas, e de solvência são inexoráveis, como a que ocorreu em 2008. A compra de ativos privados ou públicos pelos BC, oriundos das carteiras dos bancos privados, constituem indicação inequívoca desta ação. Assim, a crise de solvência (8) agregaria elementos bastantes desestabilizadores aos processos apontados acima. Ela significa emissão monetária dedicada diretamente à compra de títulos dos ativos dos bancos. Assim, de um lado, amplia a riqueza monetária, retirando títulos de circulação ao mesmo tempo em que mantém os valores dos títulos e as taxas de juros nos mercados secundários. O resultado, como ficou evidente na evolução das sucessivas operações de afrouxamento monetário $(\mathrm{QE})$, não foi a recuperação significativa do crédito, mas sobretudo da especulação. Esta é a conclusão que necessita ser incorporada à MMT: em mercados líquidos e desregulados a discricionariedade da autoridade monetária é condicionada pelos mercados. 


\section{Considerações finais}

As falhas da MMT constatadas na abordagem de circuitos parciais e simplificados se mostram mais claras nos casos nos quais os circuitos são integrados e interdependentes. O essencial nessa integração é uma postura convergente dos dois circuitos, dado que ambos e não somente o circuito público têm capacidade de criar moeda e alimentar o gasto, a renda, e a especulação. Mas, aqui também não cabe enganos, não há poder absoluto e discricionário de um circuito sobre o outro, mesmo do público sobre o privado, exceto se os mercados financeiros forem, como foram durante o regime de Bretton Woods, estritamente regulados.

Não deixa de ser paradoxal que numa teoria que se pretende minskyana, como a MMT, a moeda bancária, os ciclos de crédito e a fragilidade financeira sejam abordados de maneira lateral. Assim, por exemplo, para que o gasto, tanto público quanto privado, se expanda, levando ao crescimento significativo e permanente da renda e do emprego é necessário não só a criação de dinheiro estatal, mas também do crédito privado, por meio dos bancos. Em princípio, nada impede que isto aconteça, mas posturas mais conservadoras por parte dos bancos com restrição à criação de crédito adicional podem advir, por exemplo, para além de uma avaliação dos riscos crescentes no setor privado, de uma avaliação sobre a indesejabilidade da ampliação do gasto e da dívida públicos. Por sua vez, ciclos fortes de criação de crédito e de construção de fragilidades financeiras privadas possuem relativa independência do gasto estatal e da postura da política monetária.

Em resumo, mesmo o exame dos dois circuitos, tomados isoladamente - o do gasto público financiado monetariamente e o do gasto privado financiado a crédito - revelam de maneira peculiar as imprecisões da MMT, no que tange ao poder discricionário do Estado na fixação das taxas de juros em mercados desregulados. Nesse caso, o que se pode afirmar é que o sucesso gera o fracasso. Ou seja, fixar o espectro de taxas de juros em patamares reduzidos para garantir a sustentabilidade da dívida pública, simultaneamente à circulação da riqueza privada em mercados financeiros líquidos e desregulados, engendra bolhas especulativas recorrentes, sem necessariamente garantir o financiamento do investimento privado. Não se deve esquecer aqui o caso das economias periféricas, nas quais esta especulação tem endereço preciso: a taxa de câmbio, com uma plêiade de efeitos indesejáveis.

Do que foi dito fica como conclusão o caráter inapropriado do programa permanente de política econômica proposto pela MMT para economias financeirizadas e periféricas de alto grau de abertura financeira. Nesse contexto, é possível que suas propostas produzam mais especulação e instabilidade do que 
financiamento e crescimento em direção ao pleno emprego. Isto, todavia, não deve obscurecer a possibilidade, já apontada anteriormente, de no atual contexto de taxas de juros muito baixas, ineficácia da política monetária como instrumento de estímulo ao gasto privado e lento crescimento da renda, utilizar mais decisivamente a política fiscal e as formas não canônicas de financiamento do gasto público. Pretender ir além disto, com a instituição do programa permanente da MMT, exigiria mudanças profundas na regulação dos mercados, um eufemismo para se referir à imposição de limitações mais significativas nas formas de propriedade e usos da riqueza financeira.

\section{Referências}

Borio, C., \& Disyatat, P. (2010) "Global imbalances and the financial crisis: reassessing the role of international finance". Asian Economic Policy Review 5(2), 198-216. https://doi.org/10.1111/j.1748-3131.2010.01163.x

Carneiro, R. (2009) "O financiamento da acumulação de ativos (um esquema analítico)". Texto para discussão, n 167.

Carneiro, R. (2020) "Acumulação fictícia, especulação e instabilidade financeira (Parte II: uma reflexão sobre a financeirização a partir da literatura contemporânea". Economia e Sociedade,29(3), p. 693-717. http://dx.doi.org/10.1590/1982-3533.2020v29n3art01

Carneiro, R., \& De Conti, B. (2020) "Privilégio exorbitante e fardo compulsório (a dupla face do SMI financeirizado)". Instituto de Economia da UNICAMP, Campinas. Texto para discussão, n 395.

Chick, V. (1986) "The evolution of the banking system and the theory of saving, investment and interest." Economics of Societes. Cahiers de l'ISMEA, Serie Monnaie et Production, n 3.

Epstein, G. A. (2019) "What's wrong with modern money theory?: A policy critique". Springer.

FMI (2019) "Global financial stability report". Oct 2019. Lower for longer

Henwood, D. (2019) "Modern monetary theory isn't helping", Jacobin, 21 February, available at: https://www.jacobinmag.com/2019/02/modern-monetarytheory-isnt-helping.

Kalecki, M. (1943) "Political aspects of full employment". Political Quarterly, 14(4), p. 322-330. 
Keynes, J. M. (1930) "Treatise on money: Pure theory of money" Vol. I

Keynes, J. M. (1936 [2017]) "Teoria geral do emprego, do juro e da moeda". Saraiva Educação

Keynes, J. M. (1937) "The general theory of employment". The Quarterly Journal of Economics, 51(2), p. 209-223.

Lara Resende, A. L. (2020) "Consenso e contrassenso: Por uma economia não dogmática". Portfolio-Penguin.

Lavoie, M. (2014) "The monetary and fiscal nexus of Neo-Chartalism: a friendly critique". Journal of Economic Issues. 47(1), p. 1-32. https://doi.org/10.2753/JEI0021-3624470101

Lerner, A.P. (1943) "Functional finance and the federal debt", Social Research. 10, p. 38-51. https://www.jstor.org/stable/40981939

Minsky, H. P. (1992) "The financial instability hypothesis". The Jerome Levy Economics Institute Working Paper, n 74.

Palley, T. (2020) "What's wrong with Modern Money Theory: macro and political economic restraints on deficit-financed fiscal policy". Review of Keynesian Economics 8(4), p. 472-493. https://doi.org/10.4337/roke.2020.04.02

Prates, D. (2020) "Beyond Modern Money Theory: a Post-Keynesian approach to the currency hierarchy, monetary sovereignty, and policy space". Review of Keynesian Economics8(4), p. 494-511. https://doi.org/10.4337/roke.2020.04.03

Streeck, Wolfgang (2013) "Tempo comprado - A crise adiada do capitalismo democrático". Coimbra: Actual.

Wray, L. R. (2015) "Modern money theory: A primer on macroeconomics for sovereign monetary systems". Springer.

Wray, R (2018) "Modern Money Theory: how I came to MMT and what I include in MMT". Remarks for the 2018 MMTConference, September p. 28-30, NYC 